\title{
"Comprehensive Analysis and Comparison of Digital Current Control Techniques for Active
} Rectifiers"

CONTROLO Portuguese Conference on Automatic Control, Guimarães - Portugal, Sept. 2016.

http://link.springer.com/chapter/10.1007/978-3-319-43671-5_55

ISBN: 978-3-319-43670-8

DOI 10.1007/978-3-319-43671-5 55

This material is posted here according with:

"The Author may self-archive an author-created version of his/her Contribution on his/her own website and/or in his/her institutional repository, including his/her final version. He/she may also deposit this version on his/her funder's or funder's designated repository at the funder's request or as a result of a legal obligation, provided it is not made publicly available until 12 months after official publication."

(C) 2014 SPRINGER 


\title{
Comprehensive Analysis and Comparison of Digital Current Control Techniques for Active Rectifiers
}

\author{
Vítor Monteiro $^{1}$, João C. Ferreira ${ }^{2}$, Delfim Pedrosa ${ }^{1}$, \\ M. J. Sepúlveda ${ }^{1}$, J. C. Aparício Fernandes ${ }^{1}$, João L. Afonso ${ }^{1}$ \\ ${ }^{1}$ Centro Algoritmi - University of Minho - Guimarães, Portugal \\ \{vitor.monteiro, delfim.pedrosa, sepulveda.freitas, \\ aparicio.fernandes, joao.l.afonso\}@algoritmi.uminho.pt \\ ${ }^{2}$ ISCTE - Instituto Universitário de Lisboa - Lisboa, Portugal \\ jcaf2001@gmail.com
}

\begin{abstract}
This paper presents a comprehensive analysis and comparison of digital current control techniques for active rectifiers. These rectifiers are connected to the power grid and are controlled aiming to obtain sinusoidal grid currents and unitary power factor. In this context this paper presents the principle of operation of a full-bridge full-controlled active rectifier, which is controlled by different digital current control techniques, namely, proportional-integral (PI) in stationary frame, PI in synchronous frame, PI sinewave (PIS), feedforward, sliding mode, and predictive. These digital current control techniques are explained in detail and is established a comparison in terms of their current errors in steady-state, as well as in terms of their digital implementation using the digital signal processor (DSP) TMS320F28335 from Texas Instruments.
\end{abstract}

Keywords: Digital Current Control; Active Rectifier; PI Stationary Frame; PI Synchronous Frame; PI Sinewave; Feedforward; Sliding Mode; Predictive.

\section{Introduction}

The use of power electronics converters has been increasing for a wide range of applications, e.g., for electric mobility [1], renewable energy systems [2], power grid conditioners [3], and power factor correctors [4]. Taking into account that these converters are connected to the power grid through ac-dc converters, the grid current is the variable that must be controlled in order to adjust the active and reactive power, optimize the performance of the converter, and mitigate power quality problems [5]. For such purpose, it is necessary to use a current control technique. As consequence, new control schemes have been proposed for the aforementioned power applications. Along the last decades, several analog and digital current control techniques have been proposed with different levels of complexity [6]. Although analog techniques have fastest transient response and no delay caused by the analog-to-digital conversion, digital techniques have been explored more intensively mainly due to the advances in digital signal processors (DSP) [7]. 


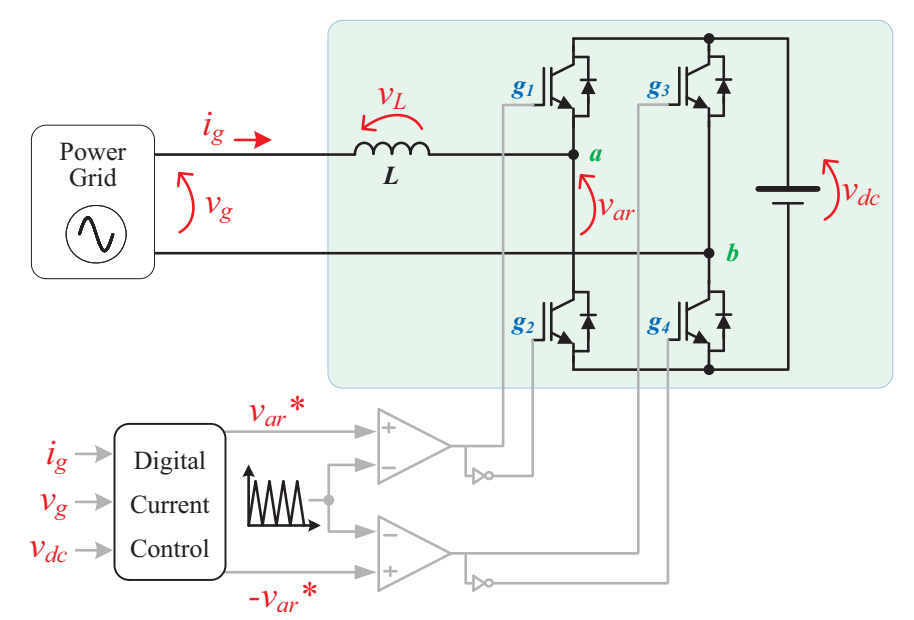

Fig. 1. Interface between the power grid and the full-bridge full-controlled active rectifier.

The classical analog current techniques applied to active rectifiers are: hysteresis and proportional-integral (PI) in stationary frame. On the other hand, the most common digital current techniques are: digital PI in stationary frame, digital PI in synchronous frame, and feedforward $[8,9,10]$. More recently, sliding mode and predictive have gained more importance for power electronics converters (e.g., active rectifiers) $[11,12,13]$. For instance, when compared with analog techniques, the main advantage of digital techniques is the possibility of including the nonlinearities of the coupling inductance, e.g., the nonlinear variation between the inductance and the current. Both analog and digital current control techniques can be used to obtain a resultant grid current with fixed or variable switching frequency. However, it is important to note that fixed switching frequency has more advantages, e.g., in the design of the passive filters [14].

In this context, this paper presents a comprehensive analysis and comparison of digital current control techniques with fixed switching frequency for a full-bridge full-controlled active rectifier, namely: PI in stationary frame, PI in synchronous frame, PI sinewave (PIS), feedforward, sliding mode, and predictive. The main goal of these techniques is to determine the voltage that the converter must produce in order to obtain zero steady-state error between the grid current and its reference after a predetermined sampling period [15].

\section{Active Rectifier: Principle of Operation}

This section introduces the principle of operation of the full-bridge full-controlled active rectifier that was used to compare the digital current control techniques. Fig. 1 shows the active rectifier connected to the power grid through an inductance.

As it can be observed in Fig. 1, in order to obtain fixed switching frequency, it is used a unipolar center-aligned pulse-width modulation (PWM) strategy, i.e., each leg of the active rectifier is controlled individually. Using this strategy, the voltage produced by the active rectifier $\left(v_{a r}\right)$ can assume three distinct values. When the IGBT $g_{I}$ 
is on (the IGBT $g_{2}$ is off) and the IGBT $g_{3}$ is on (the IGBT $g_{4}$ is off) the voltage $v_{a r}$ is 0 . When the IGBT $g_{l}$ is on (the IGBT $g_{2}$ is off) and the IGBT $g_{3}$ is off (the IGBT $g_{4}$ is on) the voltage $v_{a r}$ is $v_{d c}$. When the IGBT $g_{1}$ is off (the IGBT $g_{2}$ is on) and the IGBT $g_{3}$ is off (the IGBT $g_{4}$ is on) the voltage $v_{a r}$ is 0 . When the IGBT $g_{l}$ is off (the IGBT $g_{2}$ is on) and the IGBT $g_{3}$ is on (the IGBT $g_{4}$ is off) the voltage $v_{a r}$ is $-v_{d c}$. Taking into account the dynamic behavior of the IGBTs (i.e., transition between on and off and vice-versa) it is used a dead-time of $2 \mu \mathrm{s}$ between the IGBTs of the same leg. The characteristics of the active rectifier presented in Fig. 1 are shown in Table 1.

Table 1. Characteristics of the active rectifier.

\begin{tabular}{ccc}
\hline \hline PARAMETER & VALUE & UNIT \\
\hline \hline Power Grid Voltage $\left(v_{g}\right)$ & 230 & $\mathrm{~V}$ \\
Power Grid Frequency $(f)$ & 50 & $\mathrm{~Hz}$ \\
Sampling Frequency $\left(f_{s}\right)$ & 40 & $\mathrm{kHz}$ \\
Switching Frequency $\left(f_{s w}\right)$ & 20 & $\mathrm{kHz}$ \\
Dc-Link Voltage $\left(v_{d c}\right)$ & 400 & $\mathrm{~V}$ \\
Peak Grid Current Reference $\left(i_{g}{ }^{*}\right)$ & 20 & $\mathrm{~A}$ \\
Inductance $(L)$ & 5 & $\mathrm{mH}$ \\
\hline \hline
\end{tabular}

\section{Digital Current Control Algorithms}

This item presents in detail the principle of operation of each digital current control technique, highlighting the complexity of the digital implementation.

\subsection{Proportional-Integral (PI) in Stationary Frame}

This current control technique consists in obtaining the voltage reference $\left(v_{a r}{ }^{*}\right)$ from a PI applied to the grid current error [16]. One of the main advantages of this current control technique is the compensation of the nonlinearities of the systems, e.g., the required dead-time between IGBTs of the same leg. However, it is not possible to obtain zero stead-state error when the reference is sinusoidal. The relation between the grid current error and the grid current is established according to:

$$
i_{g}(t)=\frac{g_{P I(t)} g_{\operatorname{ar}(t)}}{g_{P I(t)} g_{\operatorname{ar}(t)}+1} i_{g}^{*}(t),
$$

where, $g_{P I}(t)$ represents the gain of the PI controller and $g_{a r}(t)$ the gain of the converter. Taking into account that $g_{a r}(t)$ assumes a constant value, the zero error is obtained adjusting the PI controller. There are some possibilities to the digital implementation of this PI, however, the most common in power electronics consists in:

$$
\begin{gathered}
m_{P}[k]=k_{p}\left(i_{g}{ }^{*}[k]-i_{g}[k]\right), \\
m_{I}[k]=k_{i} f_{s}\left(i_{g}{ }^{*}[k]-i_{g}[k]\right)+m_{I}[k-1],
\end{gathered}
$$

where, the voltage reference for the active rectifier is obtained according to: 


$$
v_{a r}^{*}[k]=m_{P}[k]+m_{I}[k] .
$$

\subsection{Proportional-Integral in Synchronous Frame}

This current control technique also consists in obtaining the voltage reference $\left(v_{a r} *\right)$ from a PI applied to the grid current error, however, this PI is applied in the $d q 0$ referential [8]. Taking into account that the variables are in the $d q 0$ referential, it is possible to obtain zero stead-state error. It is important to note that this current control technique is applied to three-phase systems, however, it can be adjusted to single-phase systems emulating two grid currents $\left(i_{g b}\right.$ and $\left.i_{g c}\right)$ from the measured grid current $\left(i_{g}\right)$. The grid current in the $d q 0$ referential is obtained using the Park transformation according to:

$$
\left[\begin{array}{l}
i_{d} \\
i_{q} \\
i_{0}
\end{array}\right]=\frac{2}{3}\left[\begin{array}{ccc}
\cos (\theta) & \cos \left(\theta-\frac{2}{3} \pi\right) & \cos \left(\theta+\frac{2}{3} \pi\right) \\
-\sin (\theta) & -\sin \left(\theta-\frac{2}{3} \pi\right) & -\sin \left(\theta+\frac{2}{3} \pi\right) \\
1 / 2 & 1 / 2 & 1 / 2
\end{array}\right]\left[\begin{array}{c}
i_{g} \\
i_{g b} \\
i_{g c}
\end{array}\right] .
$$

With these currents and the grid currents references also in the $d q 0$ referential, it is used a PI according to the aforementioned implementation (cf. equation (4)). With the voltage reference that the active rectifier must produce in the $d q 0$ referential $\left(v_{a r} d^{*}\right)$, it is used the Park invert transformation according to:

$$
\left[\begin{array}{c}
v_{\text {ar }}{ }^{*} \\
v_{\text {arb }}{ }^{*} \\
v_{\text {arc }}{ }^{*}
\end{array}\right]=\frac{2}{3}\left[\begin{array}{ccc}
\cos (\theta) & -\sin (\theta) & 1 \\
\cos \left(\theta-\frac{2}{3} \pi\right) & -\sin \left(\theta-\frac{2}{3} \pi\right) & 1 \\
\cos \left(\theta+\frac{2}{3} \pi\right) & -\sin \left(\theta+\frac{2}{3} \pi\right) & 1
\end{array}\right]\left[\begin{array}{c}
v_{\text {ar_d }} \\
v_{\text {arb } q} \\
v_{\text {arc } 0} 0
\end{array}\right],
$$

in order to obtain the voltage reference that is used in the PWM. The digital implementation of this current control technique is very similar to the implementation presented for the PI in stationary frame, however, in this case the variables are in a synchronous frame.

\subsection{Proportional-Integral Sinewave (PIS)}

This current control technique is similar to the PI in stationary frame, however, it is added a sinusoidal signal to the output result of the PI controller [10]. The sinusoidal signal is described by:

$$
g_{S}(s)=\frac{k_{S}}{s^{2}+\omega_{0}^{2}},
$$

where, $\omega_{0}$ corresponds to the frequency of the grid current frequency. Therefore, the controller is described by:

$$
g(s)=k_{p}+k_{i} \frac{1}{s}+\frac{k_{S}}{s^{2}+\omega_{0}^{2}} .
$$


The digital implementation of this current control technique is similar to the previous one, and is obtained according to:

$$
\begin{gathered}
v_{a r}{ }^{*}[k]=k_{p}\left(i_{g}{ }^{*}[k]-i_{g}[k]\right)+k_{i} f_{s}\left(i_{g}{ }^{*}[k]-i_{g}[k]\right)+ \\
+m_{I}[k-1]+\sin \left(\omega_{0}[k]\right) .
\end{gathered}
$$

\subsection{Feedforward}

This current control technique consists in adding a duty-cycle reference to the voltage reference that the active rectifier must produce aiming to reduce the influence of the PI [9]. For the aforementioned active rectifier (boost-type voltage source converter), the duty-cycle reference is defined by:

$$
\delta=1-\frac{v_{g}}{v_{d c}},
$$

where, $v_{g}$ is the power grid voltage and $v_{d c}$ is the dc-link voltage. This duty-cycle is added to a PI, resulting in a digital implementation according to:

$$
\begin{gathered}
v_{a r}{ }^{*}[k]=k_{p}\left(i_{g}{ }^{*}[k]-i_{g}[k]\right)+k_{i} f_{s}\left(i_{g}{ }^{*}[k]-i_{g}[k]\right)+ \\
+m_{I}[k-1]+\left(1-\frac{v_{g}[k]}{v_{d c}[k]}\right) .
\end{gathered}
$$

\subsection{Sliding Mode}

This current control technique consists in controlling the voltage produced by the active rectifier through a control law resulting from the circuit analysis [11]. The control law can be expressed by:

$$
u=\left\{\begin{array}{ll}
1, & S>0 \\
0, & S<0
\end{array},\right.
$$

where, $S$ is the value of the control trajectory, which is defined by:

$$
S=\alpha_{1} x_{1}+\alpha_{2} x_{2},
$$

where, $\alpha_{1}$ and $\alpha_{2}$ are the sliding coefficients and $x_{1}$ and $x_{2}$ are defined by:

$$
\left[\begin{array}{l}
x_{1} \\
x_{2}
\end{array}\right]=\left[\begin{array}{c}
i_{g}{ }^{*}-\frac{1}{L} \int\left(v_{g}-u v_{L}\right) d t \\
\int x_{1} d t
\end{array}\right] .
$$

In order to guarantee the sliding mode operation, it is required that:

$$
\lim _{S \rightarrow 0} S \dot{S}<0,
$$

where, $\dot{S}$ is the derivative of $S$. Therefore, it should be analyzed two cases: where, when $S \rightarrow 0^{+}$and when $S \rightarrow 0^{-}$. For the first case, according to (14), it results in:

$$
\alpha_{1}\left(\frac{\mathrm{d} i_{g}{ }^{*}}{\mathrm{dt}}-\frac{1}{L} v_{g}\right)+\alpha_{2}\left(i_{g}{ }^{*}-i_{g}\right)<\alpha_{1} \frac{1}{L} v_{d c} .
$$

For the second case, according to (14), it results in: 


$$
\alpha_{1}\left(\frac{\mathrm{d} i_{g}{ }^{*}}{\mathrm{dt}}-\frac{1}{L} v_{g}\right)+\alpha_{2}\left(i_{g}{ }^{*}-i_{g}\right)>0 .
$$

Combining both cases, it is obtained the control law established by:

$$
0<L \frac{\mathrm{d} i_{g}{ }^{*}}{\mathrm{dt}}-v_{g}+L \frac{\alpha_{2}}{\alpha_{1}}\left(i_{g}{ }^{*}-i_{g}\right)<v_{d c},
$$

where, the sliding coefficients are obtained doing $S=0$, i.e., according to:

$$
\frac{d x_{1}}{\mathrm{dt}}+\frac{\alpha_{2}}{\alpha_{1}} x_{1}=0,
$$

resulting in a sliding coefficients defined by:

$$
\alpha_{2}=\alpha_{1} f_{s} .
$$

The digital implementation of this current control is obtained according to:

$$
v_{a r}{ }^{*}[k]=L f_{s}\left(i_{g}{ }^{*}[k]-i_{g}{ }^{*}[k-1]\right)+L f_{s}\left(i_{g}{ }^{*}-i_{g}\right)-v_{g}[k] \text {. }
$$

\subsection{Predictive}

This current control technique consists in determining the voltage that the active rectifier must produce in order to obtain zero stead-state error between the grid current and its reference after a pre-determined number of sampling periods. Analyzing Fig. 1, it can be established:

$$
v_{g}(t)=v_{L}(t)+v_{a r}(t)
$$

where, $v_{g}, v_{L}$ and $v_{a r}$ are, respectively, the instantaneous values of the power grid voltage, the voltage across the inductance, and the voltage produced by the active rectifier. Substituting the voltage across the inductance and rearranging in order to the voltage that the active rectifier must produce, equation (22) can be rewritten by:

$$
v_{a r}(t)=v_{g}(t)-L \frac{d i_{g}(t)}{d t}(t)
$$

Taking into account that the grid current error is defined by:

$$
i_{g_{-} \text {error }}(t)=i_{g}{ }^{*}(t)-i_{g}(t),
$$

according to [17], equation (23) can be rewritten by:

$$
v_{a r}=v_{g}-L \frac{d i_{g}{ }^{*}}{d t}+L \frac{d i_{g_{-} \text {error }}}{d t} .
$$

Using the backward Euler method, the digital implementation of (25) results in:

$$
v_{\mathrm{ar}}{ }^{*}[k]=v_{\mathrm{g}}[k]-\frac{L}{T_{S}}\left(2 i_{\mathrm{g}}{ }^{*}[k]-i_{\mathrm{g}}{ }^{*}[k-1]-i_{\mathrm{g}}[k]\right) .
$$

\section{Analysis and Comparison}

Taking into account that the active rectifier under study operates with sinusoidal grid current in phase with the power grid voltage, Fig. 2(a) shows the power grid voltage 

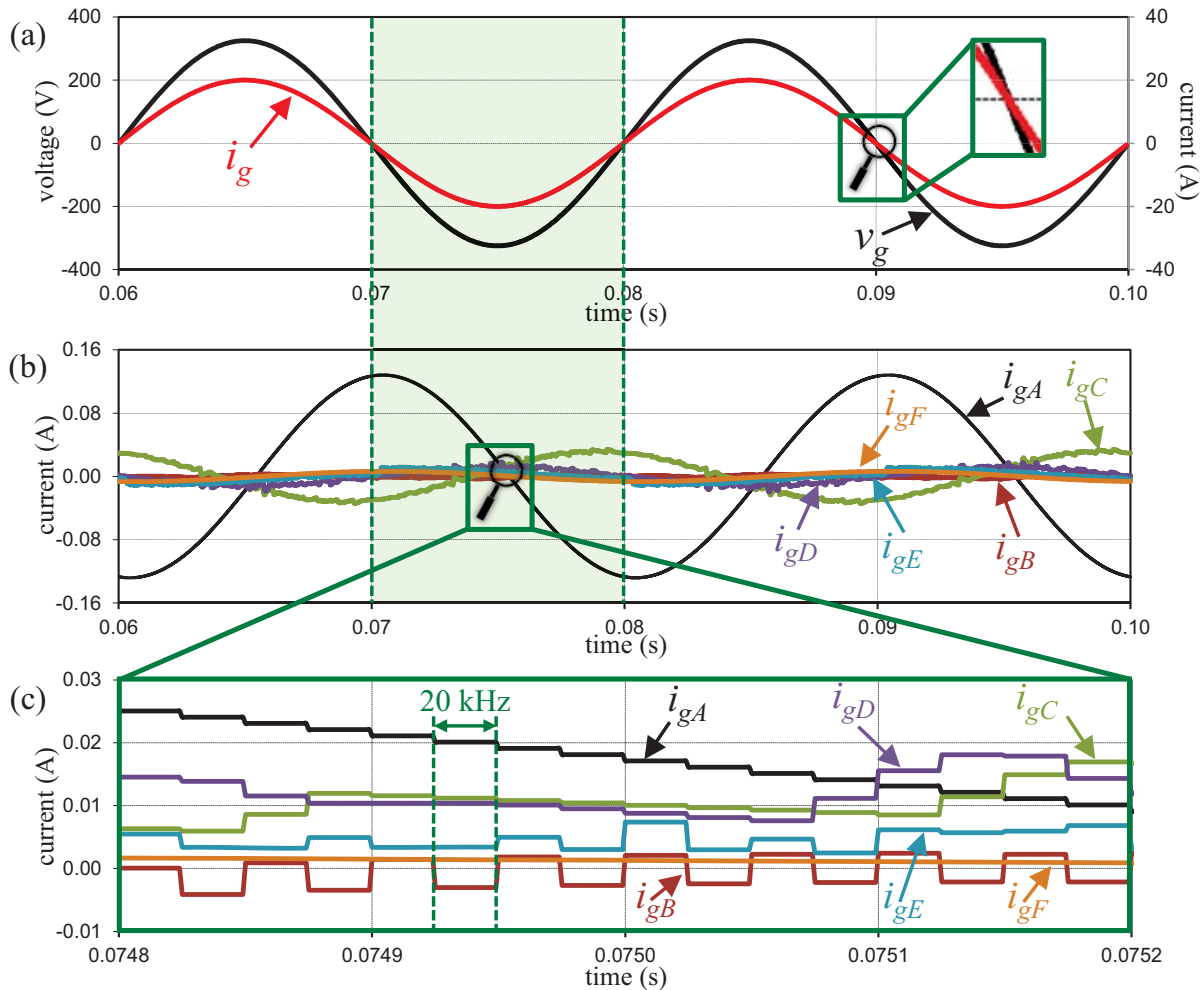

Fig. 2. Simulation results: (a) Power grid voltage $\left(v_{g}\right)$ and grid current $\left(i_{g}\right)$; (b) Digital errors of all the current control techniques; (c) Detail of the digital current errors of all the current control techniques. ( $i_{g A}$ - PI stationary frame, $i_{g B}$ - PI synchronous frame, $i_{g C}$ - PI sinewave, $i_{g D}$ - feedfoward, $i_{g E}$ - sliding mode, $i_{g F}$ - predictive).

$\left(v_{g}\right)$ and the grid current $\left(i_{g}\right)$ during $40 \mathrm{~ms}$. It is important to note that the obtained results for the grid current $\left(i_{g}\right)$ are very similar using all the aforementioned current control techniques, i.e., using these scales of current and time, it is not possible to identify differences between the current control techniques. Using a sinusoidal current reference (cf. Table 1) the measured total harmonic distortion (THD) using all the current control techniques was about $0.8 \%$ and the measured total power factor (TPF) was 0.99 . Fig. 2(b) shows in a time interval of $40 \mathrm{~ms}$ the digital current errors of all the current control techniques: $i_{g A}$ (PI stationary frame), $i_{g B}$ (PI synchronous frame), $i_{g C}$ (PI sinewave), $i_{g D}$ (feedfoward), $i_{g E}$ (sliding mode), and $i_{g F}$ (predictive). As it can be seen, the higher error is obtained with the PI in stationary frame and the lower error is obtained with the predictive control. Fig. 2(c) shows a detail of $0.4 \mathrm{~ms}$ extracted from Fig. 2(b) of the digital current errors of all the current control techniques.

Fig. 3 shows a comparison of the current control techniques in terms of the relation between the measured grid current and the error in steady state. As it can be seen, the best result is for the PI in synchronous frame and the worst case is for the PI in stationary frame. The aforementioned current control techniques were also compared in terms of the time required to perform the digital implementation. In power electronics 


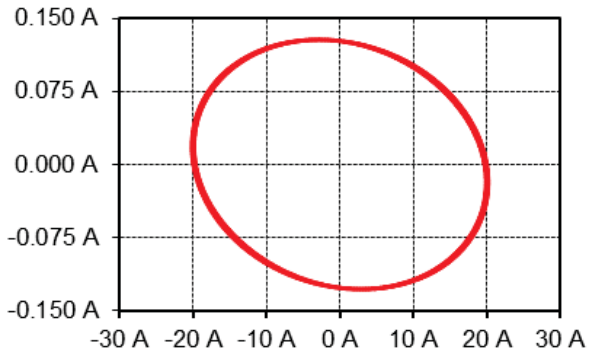

(a)



(c)

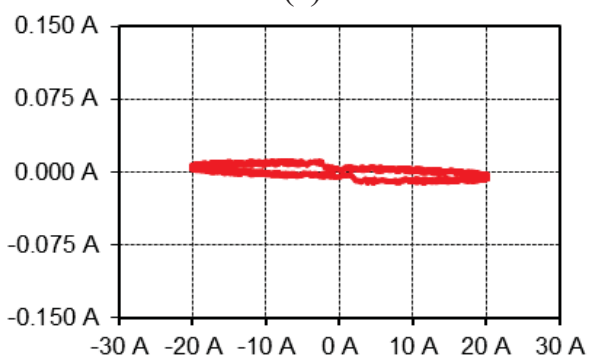

(e)

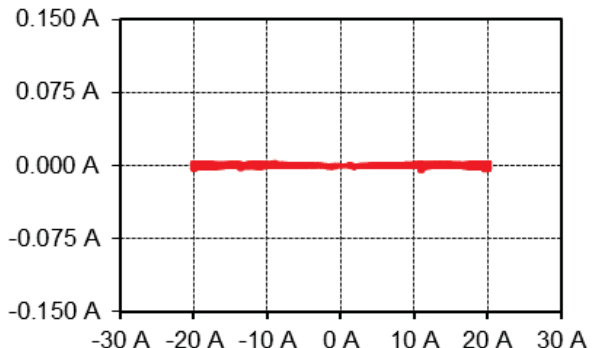

(b)

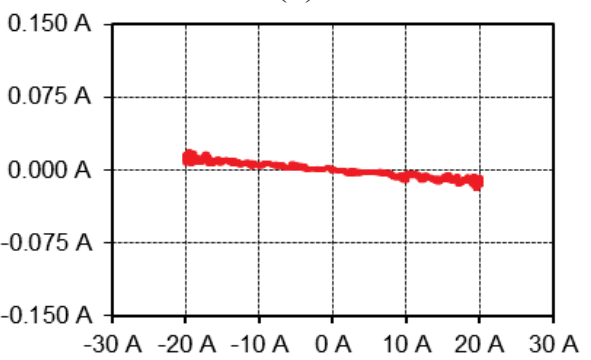

(d)

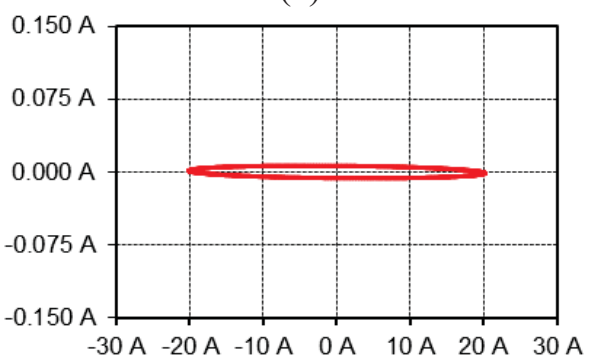

(f)

Fig. 3. Comparison of the current control techniques in terms of the relation between the measured grid current and the error in steady state: (a) PI in stationary frame; (b) PI in synchronous frame; (c) PI sinewave (PIS); (d) Feedforward; (e) Sliding mode; (f) Predictive.

applications this time is very important, since during the sampling period $[k, k+1]$ are performed other tasks besides the current control technique, e.g., analog-to-digital conversion, phase-locked loop synchronization with the power grid voltage, and application of the power theory to establish the grid current reference $\left(i_{g} *\right)$. For such purpose, all the current control techniques were programmed in the digital signal processor (DSP) TMS320F28335 from Texas Instruments. This DSP was programed for a cycle-time of $150 \mathrm{MHz}$ and a sampling frequency of $40 \mathrm{kHz}$. Table 2 shows the time period required to execute each current control technique. These time periods were measured using one of the features available in the Code Composer Studio from Texas Instruments (the software used to program the DSP). As expected, the PI in synchronous frame is the current control technique that requires more time due to the Park transformations. On the other hand, the predictive is the current control technique that requires less time due to the simple control law equation. Using the 
Table 2. Time period required to execute each current control technique in the DSP TMS320F28335.

\begin{tabular}{ccc}
\hline \hline CURRENT CONTROL & VALUE & UNIT \\
\hline \hline PI Stationary Frame & 333 & $\mathrm{~ns}$ \\
PI Synchronous Frame & 8940 & $\mathrm{~ns}$ \\
PI Sinewave & 800 & $\mathrm{~ns}$ \\
Feedforward & 1927 & $\mathrm{~ns}$ \\
Sliding Mode & 320 & $\mathrm{~ns}$ \\
Predictive & 247 & $\mathrm{~ns}$ \\
\hline \hline
\end{tabular}

aforementioned conditions for the DSP, according to Table 2, the predictive current control is almost $97.2 \%$ faster than the PI in synchronous frame.

\section{Conclusions}

This paper presents a comprehensive analysis and comparison of digital current control techniques that can be applied to control the grid current of active rectifiers. In this paper it is used a full-bridge full-controlled active rectifier to compare the different digital current control techniques, namely, proportional-integral (PI) in stationary frame, (PI) in synchronous frame, PI sinewave (PIS), feedforward, sliding mode, and predictive. These digital current control techniques are presented and explained in detail along the paper, where is also established a comparison in terms of the current error in steady-state and the time period required to execute each current control using the digital signal processor (DSP) TMS320F28335 from Texas Instruments. Using a sinusoidal current reference, the measured total harmonic distortion (THD) for all the current control techniques was about $0.8 \%$, and the total power factor was 0.99 . When the comparison is performed in terms of the relation between the measured grid current and the error in steady state, the best result is for the PI in synchronous frame and the worst case is for the PI in stationary frame. However, the PI in synchronous frame is the current control technique that requires more time to be executed in the DSP. On the other hand, the predictive is the current control technique that requires less time. The predictive current control is almost $97.2 \%$ faster than the PI in synchronous frame. For the active rectifier under study in this paper, using a PI in synchronous frame it is possible obtain zero error, however, the digital implementation is more complex and requires more computational resources.

\section{Acknowledgements}

This work has been supported by COMPETE: POCI-01-0145-FEDER-007043 and FCT - Fundação para a Ciência e Tecnologia within the Project Scope: UID/CEC/00319/2013. The PhD student Vítor Monteiro was supported by the doctoral scholarship SFRH/BD/80155/2011 granted by the FCT agency. 


\section{References}

1. Monteiro, V., Pinto, J. G., Afonso, J. L.: Operation Modes for the Electric Vehicle in Smart Grids and Smart Homes: Present and Proposed Modes. In IEEE Transactions on Vehicular Technology, vol.65, no.3, pp.1007-1020, Mar. 2016.

2. Kempton, W., Tomic, J.: Vehicle-to-Grid Power Implementation: From Stabilizing the Grid to Supporting Large-Scale Renewable Energy. ELSEVIER Journal of Power Sources, 144(1), 280-294 (2015)

3. Afonso, J. L., Couto, C., Martins, J.: Active Filters with Control Based on the p-q Theory. IEEE Industrial Electronics Society Newsletter, 47(3), 5-10 (2000)

4. Huber, L., Jang, Y., Jovanovic, M.: Performance Evaluation of Bridgeless PFC Boost Rectifier. IEEE Transactions on Power Electronics, 23(3), 1381-1390 (2008)

5. Monteiro, V., Gonçalves, H., Afonso, J. A.: Impact of Electric Vehicles on Power Quality in a Smart Grid Context. In IEEE EPQU International Conference on Electrical Power Quality and Utilisation, pp.1-6, Oct. 2011.

6. Buso, S., Malesani, L., Mattavelli, P.: Comparison of Current Control Techniques for Active Filter Applications. IEEE Transactions on Industrial Electronics, 45(5), 722-729 (1998)

7. Buso, S., Mattavelli, P.: Digital Control in Power Electronics. In Morgan \& Claypool Publishers (2006)

8. Miranda, U. A., Aredes, M., Rolim, L. G. B.: A DQ Synchronous Reference Frame Control for Single-Phase Converters. In IEEE PESC Power Electronics Specialists Conference, pp.1377-1381. IEEE Press, Recife (2005)

9. Chen, M., Sun, J.: Feedforward Current Control of Boost Single-Phase PFC Converters. IEEE Transactions on Power Electronics, 21(2), 338-345 (2006)

10. Fukuda, S., Imamura, R.: Application of a Sinusoidal Internal Model to Current Control of Three-Phase Utility-Interface Converters. IEEE Transactions on Industrial Electronics, 52(2), 420-426 (2005)

11. Tan, S. C., Lai, Y. M., Tse, C. K., Wu, C. K.: A Pulsewidth Modulation Based Integral Sliding Mode Current Controller for Boost Converters. In IEEE PESC Power Electronics Specialists Conference, pp.1-7. IEEE Press, Jeju (2006)

12. Rodríguez, J., Pontt, J., Silva, C. A., Correa, P., Lezana, P., Cortés, P., Ammann, U.: Predictive Current Control of a Voltage Source Inverter. IEEE Transactions on Industrial Electronics, 54(1), 495-503 (2007)

13. Monteiro, V., Ferreira, J. C., Melendez, A. A. N., Afonso, J. A.: Model Predictive Control Applied to an Improved Five-Level Bidirectional Converter. In IEEE Transactions on Industrial Electronics, (2016).

14. Muhlethaler, J., Schweizer, M., Blattmann, R., Kolar, J. W., Ecklebe, A.: Optimal Design of LCL Harmonic Filters for Three-Phase PFC Rectifier. IEEE Transactions on Power Electronics, 28(7), 3114-3125 (2013)

15. Bode, G. H., Loh, P. C., Newman, M. J., Holmes, D. G.: An Improved Robust Predictive Current Regulation Algorithm. In IEEE Transactions on Industrial Applications, vol.41, no.6, pp.1720-1733, (2005).

16. Brod, D. M., Novotny, D. W.: Current Control of VSI-PWM Inverters. IEEE Transactions on Industrial Applications, IA-21(3), 562-570 (1985)

17. Orts-Grau, S., Gimeno-Sales, F. J., Abellan-Garcia, A., Segui-Chilet, S., Alfonso-Gil, J. C.: Improved Shunt Active Power Compensator for IEEE Standard 1459 Compliance. IEEE Transactions on Power Delivery, 25(4), 2692-2701 (2010) 